\title{
Light Environment Simulation of Xinyang Traditional Residence in Haicang District, Xiamen
}

\author{
He Miao ${ }^{1, a}$ \\ ${ }^{1}$ College of Civil Engineering and Architecture, Xiamen University of Technology, Xiamen 361024, China
}

\begin{abstract}
Applying the analysis software ECOTECT, which is related to the constructing environment, the paper attempts to make a simulated experiment on the daylight environment factors in traditional residence in Xinyang Village. The conclusion is that the lighting coefficient of local dwellings cannot reach the regulation design standard of daylight, and daylight uniformity of most dwellings is poor. Towards these problems, some influencing factors are put forward through the field research, and by using ECOTECT, we get the distribution diagram and distribution percentage of lighting coefficient, and then proceed the quantization and the merits and demerits of each variable, which can offer a reference for the dwelling design.
\end{abstract}

\section{Instruction}

Daylight environment is closely linked to people's life, which not only affects people's physical health, but psychological health as well. It is an important indicator of creating the comfortable indoor environment. In recent years, with the gradual execution of the new national rural policy and the improvement of residents' quality of life, people pay much attention to the indoor daylight environment of traditional residence. On account of the living habit of residents in early stage, high-density construction of towns and houses, and the layout of construction itself, the current situation of natural light of traditional residence in Southern Fujian needs urgen improving. The paper selects the traditional residence in Xinyang Village, Haicang District, Xiamen as the object of study, and applies the analysis software ECOTECT to proceed the simulated analysis on the indoor daylight, and studies the influence of the daylight on people's life, and based on this, the paper puts forward the daylight design strategies in the construction of residence in this region.

\section{The current situation of traditional residence in Xinyang Village}

Haicang District is located in the southwest of Xiamen, Fujian province, which belongs to Jindong Plain. Its sunshine duration is between 1500-2400 hours throughout the year, which belongs to the IV in light climate division, and its sunshine duration can exceed $2100 \mathrm{~h}$ per year,which means light resource is quite abundant.

In the village, although there exist many undamaged traditional residence, the indoor light has a throng of problems. A large portion of the reason why many aborigines move away from the old houses, leaving them empty is that the indoor light is poor.Hence, it accelerates the aging of the buildings. The aborigines said that though artificial lighting can solve this problem, people would feel more comfortable and pleasant in the natural

a Corresponding author: 88407567@qq.com 
light.

Through the field research, we tentatively find the influencing factors that lead to the poor light:

-First, due to the local geographical characteristics and folk customs, the residences have bright lobby and dim bedroom (the lobby functions as sacrifice and living room, so the lobby which orients the side of the inner garth does not have walls, but open instead; however, in order to reduce the solar radiant heat, especially reduce the window area in the room and kitchen, the rooms have to be dim.).

-On the structure, the proportion between window and land, the location of the window, sunshade and indoor reflectance ratio are also vital factors.

-On its layout, the orientation and the density of the building are also included in the influence factors.

The research will apply the analysis software ECOTECT to verify these influence factors and draw conclusions.

\section{Indoor daylight simulation of traditional residence in Xinyang Village}

\subsection{Simulating object}

We select Chen's house, one of the typical traditional residence in Xinyang Village, as the object of this study. This building orients north by east $10^{\circ}$, which is made up of red brick, with two-entrances, three standard width and one layer height. Its plane layout presents as a quadrangle courtyard (see Figure 1 and Figure 2). Chen's house has the most typical features, that is, the subject is a composite structure with masonry and wood. Except the lobby, the exterior is entire open. The windows are few and the apertures are small. The windows in the bedroom do not exceed 0.2. The density between the buildings is large. Compared with the other residences, it belongs to such kind of the residence with steep slopes and long eave in order to be shaded and insulated.

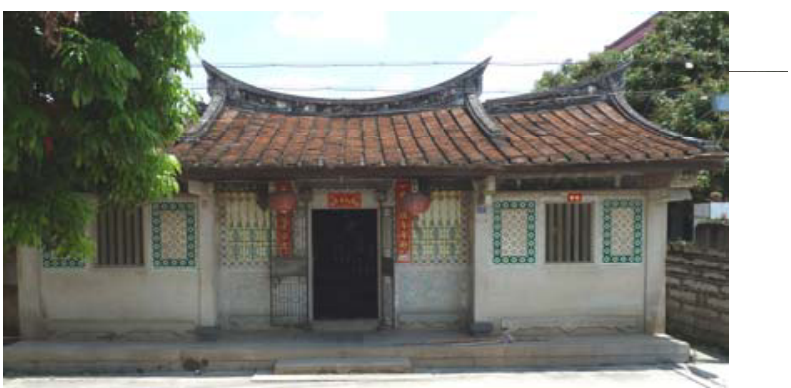

Figure 1. Exterior of traditional residence Chen's

\subsection{Experiment conditions and methods}

(1) Basic conditions: its northern latitude is 24.27 , and the east longitude is 118.06 . It is 12:00 in the high noon, July 21 st. The coefficient $\mathrm{K}$ of light climate is 1.10.

(2) The indoor parameter: The ceilings in Chen's house are made up of brown wood, and the floors are red brick. And the walls are painted as cement mortar, with reflection coefficient $0.3,0.33,0.32$ respectively. From the investigation, the cleanliness degree of the window is quite low, and some of them are fencing windows, so the cleanliness is set as 0.75 .

(3) The model of sky illumination: in the process of design, the model of sky illumination is the whole-cloud, and its critical illumination in the outside is 4500lx. In this calculative model, the natural light in the outside is only the diffusion light, which cannot form the shade, so the orientation of the window does not have any effect on the indoor daylight.

(4) The selection of simulating area: in Southern Fujian, in the house with two-entrance, three standard width, the large room is used as the main bedroom, and Jutou (Pinyin, a room used as kitchen) is used as kitchen, and the main hall is used as living room. Because the orientation of the window could not affect the experiment, three rooms in Chen's house can be respectively simplified as three simulating zones A, B, C (Figure2) .

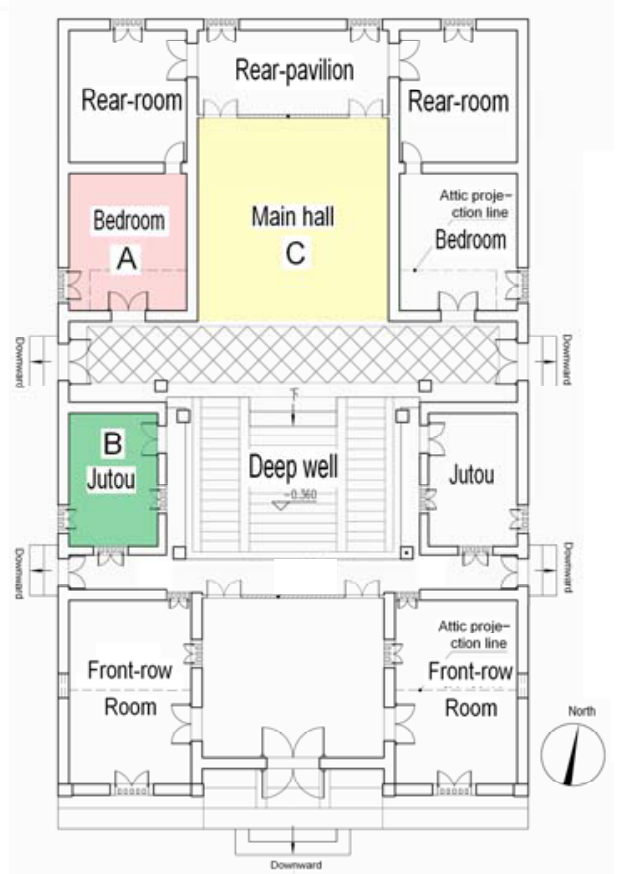

Figure 2. Ichnography of the traditional residence Chen's House 
(5) Experiment methods: This simulation uses grid method, and chooses the plane height $0.8 \mathrm{~m}$, and then analyzes the sunshade, window and the indoor reflectance ratio.

Table 1.Daylight standard value for residential buildings

\begin{tabular}{|c|c|c|c|c|c|}
\hline \multirow{3}{*}{$\begin{array}{c}\text { Lighting } \\
\text { Level }\end{array}$} & \multirow{3}{*}{ Rooms } & \multicolumn{4}{|c|}{ Sidelighting } \\
\hline & & \multicolumn{2}{|c|}{$\begin{array}{c}\text { Old minimum value } \\
\text { of d lighting } \\
\text { coefficient } \\
(\%)\end{array}$} & \multicolumn{2}{|c|}{$\begin{array}{l}\text { New minimum value } \\
\text { of lighting coefficient } \\
(\%)\end{array}$} \\
\hline & & $\begin{array}{l}\text { Standard } \\
\text { value }\end{array}$ & $\begin{array}{c}\text { Corrected } \\
\text { value }\end{array}$ & $\begin{array}{c}\text { Standard } \\
\text { value }\end{array}$ & $\begin{array}{c}\text { Corrected } \\
\text { value }\end{array}$ \\
\hline IV & $\begin{array}{l}\text { Living } \\
\text { room } \\
\text { Bedroom, } \\
\text { Study, } \\
\text { Kitchen }\end{array}$ & 1.0 & 0.91 & 2.0 & 1.82 \\
\hline V & $\begin{array}{l}\text { Toilet, } \\
\text { Aisle, } \\
\text { Dining } \\
\text { room, } \\
\text { Staircase }\end{array}$ & 0.5 & 0.45 & 1.0 & 0.91 \\
\hline
\end{tabular}

\subsection{Simulating results}

Because the outward illumination is changing, the indoor illumination is also changing; thus, the result here is not fixed. And there are two indicators to evaluate the light environment: the indoor lighting coefficient and the uniformity of illumination. So the simulating experiment will apply the indoor lighting coefficient and the uniformity of illumination to summarize the changing rules and the lighting conditions of each zone. ECOTECT presents the results as follows:

\subsubsection{Minimum value of lighting coefficient}

In architectural lighting design standards GB50033-2013, as for minimum value of lighting coefficient (Cmin), that in bedroom and living room should not be lower than
$1.82 \%$, and that toilet, passage, staircase and dining room should not be lower than $0.91 \%$ (See Table 1).

From the simulating analysis, we get that Cmin of the bedroom A is $0.07 \%$, and Cmin of the left Jutou B is $0.09 \%$, and $\mathrm{Cmin}$ of the main hall $\mathrm{C}$ is $0.81 \%$. The former two, A and B, cannot meet the daylight design standard, and though $\mathrm{Cmin}$ of the main hall $\mathrm{C}$ is higher than that of $\mathrm{A}$ and $\mathrm{B}$, it is still lower than the national rules for the daylight. It is 12:00, which is the best time for the daylight throughout the day, so at other time, zone A, B and $\mathrm{C}$ still cannot meet the daylight requirement.

\subsubsection{Uniformity of daylight}

According to Figure3, 4, 5 and Table 2, the variation range of daylight coefficient can be divided into ten classes. Table 2 presents the daylight condition of room A, whose variation range of daylight coefficient is between $0 \%$ and $20 \%$, and the amplitude of variation is $20 \%$. The range $0 \sim 2 \%$ occupies $80.13 \%$, but this indoor space still cannot satisfy the requirement. Although the zone near the window is brighter and changes obviously, the illumination of the whole room remains low and it is not distributed enough, either.

The daylight condition of Jutou B is reflected in Figure 3, whose variation range of daylight coefficient is also between $0 \%$ and $20 \%$, and the amplitude of variation is $20 \%$. The range $0 \sim 2 \%$ occupies $80.00 \%$, but this indoor space still cannot satisfy the requirement. The illumination of the whole room is low, but the illumination of the daylight opening is high. The daylight opening is far away, so the daylight uniformity of the whole room is still poor.

Figure 4 shows the daylight condition of main hall $\mathrm{C}$. Because it is lighting indirectly through Zisun alley, the variation range of daylight coefficient centers on the

Table 2. Percentage of the original lighting coefficient of each test point

\begin{tabular}{|c|c|c|c|c|c|c|c|c|c|c}
\hline $\begin{array}{c}\text { Test point } \\
\text { Lighting coefficient } \\
(\mathbf{\%})\end{array}$ & $\mathbf{0 \sim 2}$ & $\mathbf{2 \sim 4}$ & $\mathbf{4 \sim 6}$ & $\mathbf{6} \sim \mathbf{8}$ & $\mathbf{8} \sim \mathbf{1 0}$ & $\mathbf{1 0 \sim 1 2}$ & $\mathbf{1 2} \mathbf{1 4}$ & $\mathbf{1 4 ~ 1 6}$ & $\mathbf{1 6} \mathbf{1 8}$ & $\mathbf{1 8} \mathbf{2 0}$ \\
\hline Region A(Bedroom) & $80.13 \%$ & $10.27 \%$ & $3.20 \%$ & $1.47 \%$ & $1.07 \%$ & $0.80 \%$ & $0.67 \%$ & $0.53 \%$ & $0.40 \%$ & $0.53 \%$ \\
\hline Region B(Kitchen) & $82.00 \%$ & $8.53 \%$ & $2.67 \%$ & $2.00 \%$ & $0.93 \%$ & $1.20 \%$ & $0.40 \%$ & $0.93 \%$ & $0.53 \%$ & $0.27 \%$ \\
\hline Region C(Jutou) & $10.13 \%$ & $38.13 \%$ & $43.47 \%$ & $8.27 \%$ & 0 & 0 & 0 & 0 & 0 & 0 \\
\hline
\end{tabular}


former four classes, that is, the variation range of daylight coefficient is between $0 \%$ and $8 \%$, and the amplitude of variation is $8 \%$. The lighting coefficient between

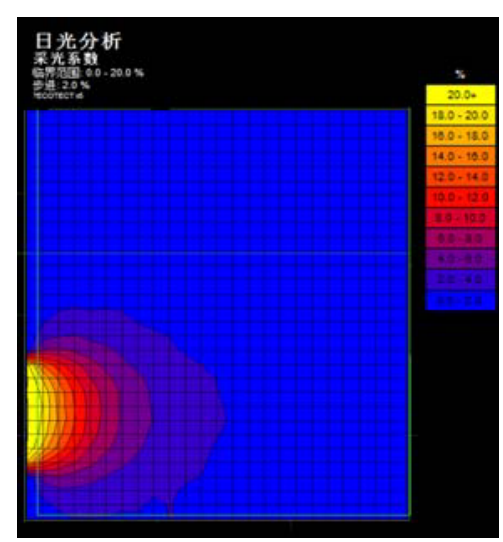

Figure 3. Region A's lighting coefficient changing curve chart

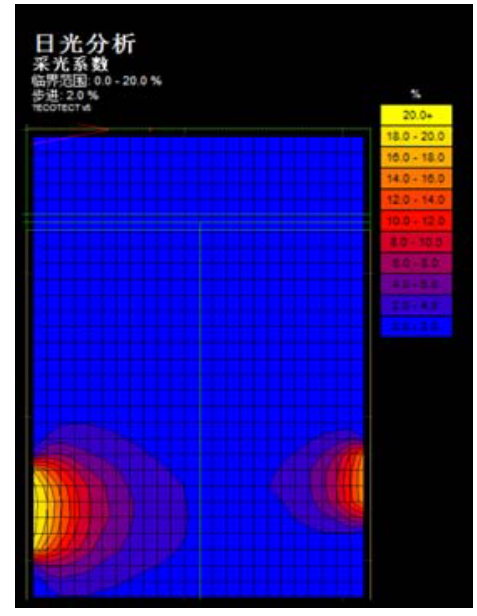

Figure 4. Region B's lighting coefficient changing curve chart

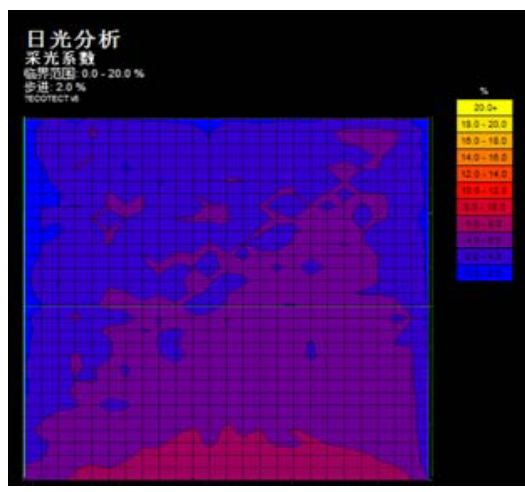

Figure 5. Region C's lighting coefficient changing curve chart
$0 \%-2 \%$ only occupies $0.86 \%$, and except for this, the other spaces all meet the daylight requirement, and the uniformity of daylight along the room is high. The simulating results reflect the feature "bright lobby and dim bedroom" of residence in Southern Fujian.

\section{Optimization simulation of light environment}

The side of the main hall is open and its window is high, so the optimizable space is not that much; while, as minor space, Jutou is primarily used as kitchen and storeroom. The left room is used as main space, whose fuction is like main bedroom in nowadays; thus, we select zone A, the main bedroom, as our object to study the optimization simulation of light environment, and then observe the influence each variable has on the indoor daylight. Taking the difficulty of reforming the indoor daylight environment of traditional residence into consideration, and following the principles that styles and features should be protected during the reforming of traditional residence, we can select the variable which is harmonious with the local styles and features.

\subsection{Opening the door}

Since the climate of Southern Fujian is hot in summer and warm in winter, it has longer sunlight time in summer. Local traditional residences are primarily designed to shield the sun and summer heat for the sake of lessened solar radiant heat, especially minimizing the windows in the room and kitchen, which results in dim indoor environment. Meanwhile, leave the side entrance that is beneath the eave and orients courtyard open. By doing so, it is effective to avoid direct sunlight and good for ventilation. The simulation results are shown in Figure 6 and Table 3: as no sunshade measures on windows and high illumination about, the lighting coefficient near the window appears its variability, mainly between $2 \%$ and $20 \%$. Whereas, for the reason that the outward side entrance which is not only under the eave but also has Jutou shade from the sun, the lighting coefficient near the

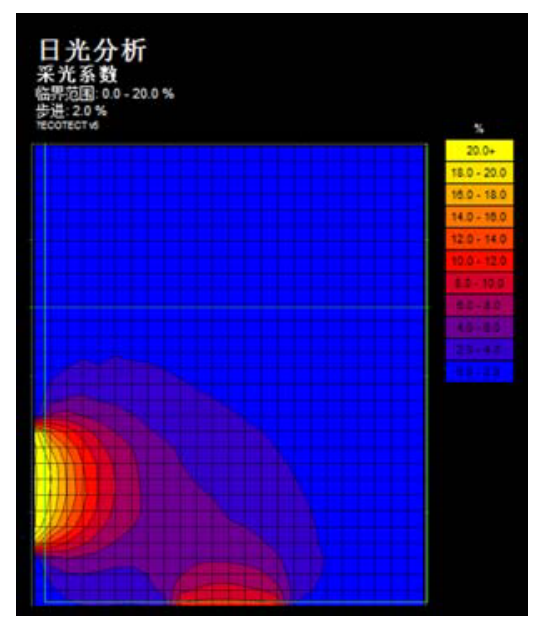

Figure 6. Region A's lighting coefficient changing curve chart of opening the door

door varies from $2 \%$ to $12 \%$. 
On the whole, Table 3 shows that the lighting coefficient distribution from classes of $2 \% \sim 4 \%, 4 \% \sim$ $6 \%, 6 \% \sim 8 \%, 8 \% \sim 10 \%$ and $10 \% \sim 12 \%$ have increased to some certain extent, at the same time, the value from 0 to $2 \%$ is reduced by $11.06 \%$, but still accounts for
$69.07 \%$ of daylight area. The daylight area that is below national minimum standard is yet the majority.

Therefore, opening the door only improves partial illumination of the room, but contributes little to the overall illumination and lighting uniformity of the room.

Table 3. Distribution percentage comparison for lighting coefficient of the bedroom ( Close and open door as variable)

\begin{tabular}{|c|c|c|c|c|c|c|c|c|c|c|}
\hline $\begin{array}{c}\text { Test point } \\
\text { Lighting coefficient } \\
(\mathbf{\%})\end{array}$ & $\mathbf{0 ~ 2}$ & $\mathbf{2 \sim 4}$ & $\mathbf{4 \sim 6}$ & $\mathbf{6} \sim \mathbf{8}$ & $\mathbf{8} \sim \mathbf{1 0}$ & $\mathbf{1 0 ~ 1 2}$ & $\mathbf{1 2 ~ 1 4}$ & $\mathbf{1 4 ~ 1 6}$ & $\mathbf{1 6} \mathbf{1 8}$ & $\mathbf{1 8} \mathbf{2 0}$ \\
\hline $\begin{array}{c}\text { Region A(Close the } \\
\text { door) }\end{array}$ & $80.13 \%$ & $10.27 \%$ & $3.20 \%$ & $1.47 \%$ & $1.07 \%$ & $0.80 \%$ & $0.67 \%$ & $0.53 \%$ & $0.40 \%$ & $0.53 \%$ \\
\hline $\begin{array}{c}\text { Region A(Open the } \\
\text { door) }\end{array}$ & $69.07 \%$ & $12.67 \%$ & $8.40 \%$ & $3.20 \%$ & $1.73 \%$ & $1.73 \%$ & $0.80 \%$ & $0.53 \%$ & $0.40 \%$ & $0.40 \%$ \\
\hline $\begin{array}{c}\text { D-value(Open-Close } \\
\text { the door) }\end{array}$ & $-11.06 \%$ & $2.40 \%$ & $5.20 \%$ & $1.73 \%$ & $0.66 \%$ & $0.97 \%$ & $0.13 \%$ & 0 & 0 & $-0.07 \%$ \\
\hline
\end{tabular}

\subsection{Open the door and remove the cornice}

As most sunshade is situated towards south(with door, facing courtyard and overhang eave is relatively huge, while there is little sunshade on the side of eastward window. So opening the door is to illuminate what effects no-sunshade measure has on the daylight. We found that compared with mere door-opening measure, daylight uniformity has a slight increase (see Table 4). But if compare Figure 6 with Figure 7, we cannot find any evident change on the eastern side, but the side of entrance. That is because the cornice above the eastern window is small and distant from the window, however, the one on the side of entrance is deep and lower than the window. Therefore, illumination on the entrance changes greatly.

Hence, the measure of opening the door and

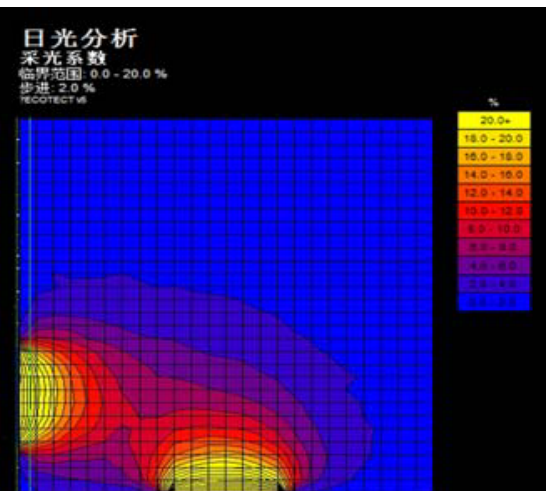

Figure 7. Region A's lighting coefficient changing curve chart of opening the door and removing the cornice

removing the sunshade has little influence on indoor light uniformity, but has significant impact on illumination.

\subsection{Increase glass tiles and demolish attic}

Table 4. Distribution percentage comparison for lighting coefficient of the bedroom( Open door and remove cornice as variable)

\begin{tabular}{|c|c|c|c|c|c|c|c|c|c|c|}
\hline $\begin{array}{c}\text { Test point } \\
\text { Lighting coefficient } \\
\text { (\%) }\end{array}$ & $\mathbf{0} \mathbf{2}$ & $\mathbf{2} \mathbf{4}$ & $\mathbf{4 \sim 6}$ & $\mathbf{6} \mathbf{8}$ & $\mathbf{8} \sim \mathbf{1 0}$ & $\mathbf{1 0 ~ 1 2}$ & $\mathbf{1 2 ~ 1 4}$ & $\mathbf{1 4 ~ 1 6}$ & $\mathbf{1 6 ~ 1 8}$ & $\mathbf{1 8 \sim 2 0}$ \\
\hline $\begin{array}{c}\text { Region A(Open the } \\
\text { door) }\end{array}$ & $80.13 \%$ & $10.27 \%$ & $3.20 \%$ & $1.47 \%$ & $1.07 \%$ & $0.80 \%$ & $0.67 \%$ & $0.53 \%$ & $0.40 \%$ & $0.53 \%$ \\
\hline $\begin{array}{c}\text { Region A(Open door } \\
\text { and remove the } \\
\text { cornice })\end{array}$ & $69.07 \%$ & $12.67 \%$ & $8.40 \%$ & $3.20 \%$ & $1.73 \%$ & $1.73 \%$ & $0.80 \%$ & $0.53 \%$ & $0.40 \%$ & $0.40 \%$ \\
\hline $\begin{array}{c}\text { D-value(Open the } \\
\text { door-Open door and } \\
\text { remove cornice) }\end{array}$ & $-11.06 \%$ & $2.40 \%$ & $5.20 \%$ & $1.73 \%$ & $0.66 \%$ & $0.97 \%$ & $0.13 \%$ & 0 & 0 & $-0.07 \%$ \\
\hline
\end{tabular}


Taking into account the fact that the skylight efficiency is higher than that of side-window lighting, and the roof of Chen's house is wooden-framed with red tiles on, so the red brick tiles can be replaced by glass ones. The simulation result after increasing the amount of tiles is shown in Figure 8:because of the wooden attic's shade, when tiles increased, partial illumination has somewhat improved, but beneath the projected area in the attic the illumination is still very low, nor is the indoor illuminate uniformity. In the meantime, considering the attic is now available as storeroom full of sundries and dust, inconvenient for cleaning but easy to remove, it is suggested to increase tiles simultaneously demolish the

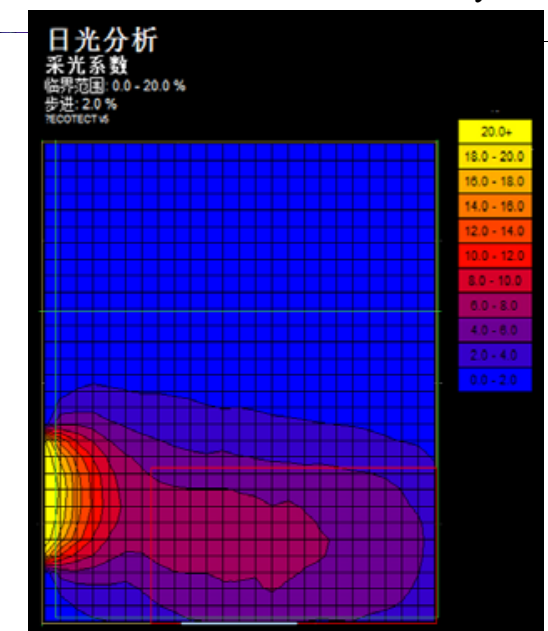

Figure 8. Region A's lighting

coefficient changing curve chart of increasing glass tiles attic for better lighting effects. As shown in Figure 9 the simulation result after tearing down the attic, daylight uniformity and illumination have notably improved. The distribution coefficient in the class of $0 \sim 2 \%$ is $0,2 \% \sim 4 \%$ is only $1.87 \%$, and $4 \% \sim 6 \%, 6 \% \sim 8 \%, 8 \% \sim 10 \%$ are respectively increased by $19.20 \%, 38.06 \%, 22.53 \%$. The area ratio of lighting coefficient has improved much and the lighting coefficient is mainly from $6 \% \sim 8 \%$ ( See Table 5).

It proves that the measure of increasing tiles and demolishing attic can significantly improve the indoor illumination and lighting uniformity.

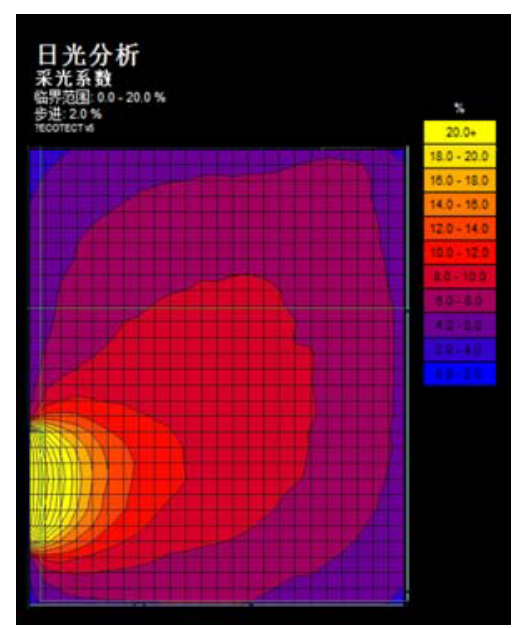

Figure 9. Region A's lighting

coefficient changing curve chart of

removal attic and increased glass tiles

Table 5. Distribution percentage comparison for lighting coefficient of the bedroom

( Removal attic and increased glass tiles as variable)

\begin{tabular}{|c|c|c|c|c|c|c|c|c|c|c|}
\hline $\begin{array}{c}\text { Test point } \\
\text { Lighting coefficient } \\
\text { (\%) }\end{array}$ & $\mathbf{0 \sim 2}$ & $\mathbf{2 \sim 4}$ & $\mathbf{4} \mathbf{6}$ & $\mathbf{6 \sim 8}$ & $\mathbf{8} \mathbf{1 0}$ & $\mathbf{1 0 \sim 1 2}$ & $\mathbf{1 2 ~ 1 4}$ & $\mathbf{1 4 ~ 1 6}$ & $\mathbf{1 6} \mathbf{1 8}$ & $\mathbf{1 8} \mathbf{2 0}$ \\
\hline $\begin{array}{c}\text { Region A(Open the } \\
\text { door) }\end{array}$ & $80.13 \%$ & $10.27 \%$ & $3.20 \%$ & $1.47 \%$ & $1.07 \%$ & $0.80 \%$ & $0.67 \%$ & $0.53 \%$ & $0.40 \%$ & $0.53 \%$ \\
\hline $\begin{array}{c}\text { Region A(Removal } \\
\text { attic and increased } \\
\text { glass tiles) }\end{array}$ & $69.07 \%$ & $12.67 \%$ & $8.40 \%$ & $3.20 \%$ & $1.73 \%$ & $1.73 \%$ & $0.80 \%$ & $0.53 \%$ & $0.40 \%$ & $0.40 \%$ \\
\hline $\begin{array}{c}\text { D-value(Open the } \\
\text { door- removal attic } \\
\text { and increased glass }\end{array}$ & $-11.06 \%$ & $2.40 \%$ & $5.20 \%$ & $1.73 \%$ & $0.66 \%$ & $0.97 \%$ & $0.13 \%$ & 0 & 0 & $-0.07 \%$ \\
\hline
\end{tabular}

\subsection{Improve the indoor reflectance ratio}

Interior decoration materials is dated and gloom, with brown wooden-structured ceiling and attic, red-bricked floor and cement-mortared wall. Their reflection coefficients are respectively set as $0.3,0.33$ and 0.32 .
From the research, we explore that the cleanliness of windows is quite low, so it should be set to 0.75 . Because of the dim room found in the field research, interior material's reflectance ratio is heightened to do comparative research in the simulation. Assuming they are all whitewashed walls, whitewashed attic's bottom 
side and the ceiling, thus the reflection coefficient of wall and attic plate is changed to 0.75 , besides, window cleanliness is altered to 0.9 (clean). As is shown in Table 6 and Figure 10 the simulation

results,daylight area that is less than the national standard is reduced by $63.46 \%$, lighting area between $2 \%$ and $4 \%$ is increased by $56.40 \%$, which means the lighting effect has obviously improved.

From Figure 10 we can analyze that except illumination in the daylight opening remains unchanged, others are even, most of which are

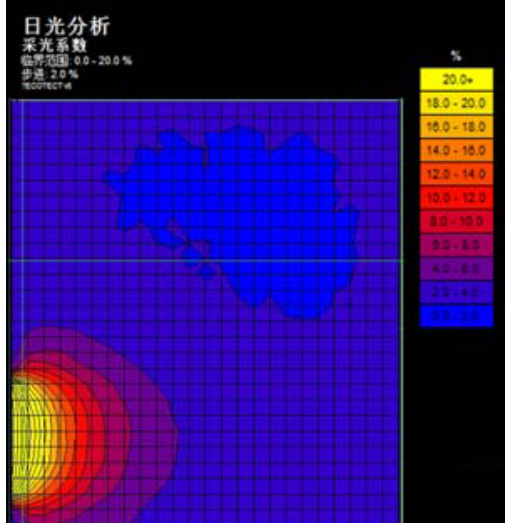

Figure 10. Region A's Lighting coefficient change curve of improving the indoor reflection ratio

Table 6. Distribution percentage comparison for lighting coefficient of the bedroom (Raise reflectance ratio as variable)

\begin{tabular}{|c|c|c|c|c|c|c|c|c|c|c|}
\hline $\begin{array}{c}\text { Test point } \\
\text { lighting coefficient } \\
(\%)\end{array}$ & $0 \sim 2$ & $2 \sim 4$ & $4 \sim 6$ & $6 \sim 8$ & $8 \sim 10$ & $10 \sim 12$ & $12 \sim 14$ & $14 \sim 16$ & $16 \sim 18$ & $18 \sim 20$ \\
\hline $\begin{array}{c}\text { Region } \mathrm{A}(\text { Open the } \\
\text { door })\end{array}$ & $80.13 \%$ & $10.27 \%$ & $3.20 \%$ & $1.47 \%$ & $1.07 \%$ & $0.80 \%$ & $0.67 \%$ & $0.53 \%$ & $0.40 \%$ & $0.53 \%$ \\
\hline $\begin{array}{l}\text { Region A( Raise } \\
\text { reflectance ratio) }\end{array}$ & $69.07 \%$ & $12.67 \%$ & $8.40 \%$ & $3.20 \%$ & $1.73 \%$ & $1.73 \%$ & $0.80 \%$ & $0.53 \%$ & $0.40 \%$ & $0.40 \%$ \\
\hline $\begin{array}{l}\text { D-value(Open the } \\
\text { door-Raise }\end{array}$ & $-11.06 \%$ & $2.40 \%$ & $5.20 \%$ & $1.73 \%$ & $0.66 \%$ & $0.97 \%$ & $0.13 \%$ & 0 & 0 & $-0.07 \%$ \\
\hline
\end{tabular}

between $2 \%$ and $4 \%$. There is only one side window in the largest room and near the southeast corner of the east wall, so the dimmest place in the room (i.e. the lowest lighting level $0-2 \%$ ) are mainly distributed diagonally closed to the window, accounting for only $16.67 \%$ daylight area. Therefore, to improve the reflection ratio of the wall space can significantly improve the indoor lighting uniformity, furthermore, substantially reduce the lighting coefficient space that is not up to the standard.

\subsection{Variable comparison}

According to analysis of the simulation results and Figure 11, we know that opening the door and removing the sunshade can improve the illumination, but have poor effects on better daylight uniformity.

The measure that mere increase the amount of glass tiles can raise the illumination and daylight uniformity for places other than the shaded area of attic. While the measure of enhancing interior reflectance ratio and demolishing the attic can much improve the overall indoor lighting uniformity, meanwhile reduce the space whose lighting coefficient cannot satisfy the standard, especially the latter measure.

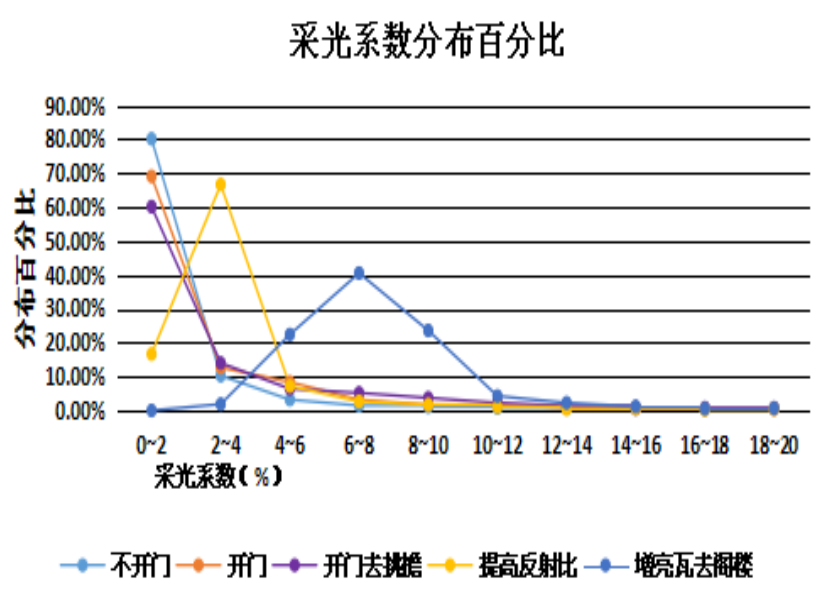

Figure 11. Lighting coefficient changing curve of improving the indoor reflection ratio of Region A

\section{Conclusions}

This research is done by ECOTECT, a built environment 
analysis software, to do simulated experiment on factors that affect indoor luminous environment of traditional residence in Southern Fujian. It finds that generally most of them cannot meet the national design standard of daylight, either poor is the most indoor lighting uniformity. And we also use the indoor lighting coefficient's distribution diagram and per centum that analyzed by ECOTECT to do quantitative analysis and comparison on elements that affect Southern Fujian traditional residence, which is thought to provide a reference for lighting design in newly constructed residence

\section{References}

1. He Miao. The analysis on the thermal environment and energy Conservation of Masonry-wood residence in southern Fujian. The Journal of Xiamen
University of Technology, 2015,6(23):56-62.

2. Ministry of Construction of People's Republic of China. Architectural Lighting Design Standards GB50033-2013. Beijing: China Building Industry Press, 2013:13.

3. National Standard GB5700-1985 The measuring Methods of indoor illumination.

4. Architectural Physics. Guangzhou: The Press of South China University of Technology, 2002:202244.

5. Lin Zurui, Li Hengyan, Simulation and study on the indoor natural lighting of traditional residences in Yingtan Village, Xingtai, Hebei Province. Huazhong Architecture, 2013(10):36-40. 